\title{
On the relationship between the rare moss Bryum marratii and a dune aquifer
}

Des A. Callaghan ${ }^{1}$, Gareth Farr ${ }^{2}$

${ }^{1}$ Bryophyte Surveys Ltd, Stroud, UK, ${ }^{2}$ British Geological Survey, Cardiff, UK

Correspondence to: Des A. Callaghan, 65 Belle Vue Road, Stroud, Gloucestershire, UK. Email: des.callaghan@bryophytesurveys.co.uk

The first detailed ecological investigation of the rare moss Bryum marratii Wilson was undertaken only very recently, at two sites in south Wales (Callaghan \& Farr, in press). Results showed occupancy of a niche that is unusual amongst bryophytes, within the upper edge of saltmarsh, where colonies were inundated by seawater many times, 32-128 events $\mathrm{yr}^{-}$ ${ }^{1}$, during spring tides, spending an average 3.6 day $^{-1} \mathrm{yr}^{-1}$ submerged. After that study, the opportunity arose for a further short piece of research, reported in this note. The aim is to investigate a possible relationship between the habitat of the species and a dune aquifer.

Whiteford Burrows ( $\left.51^{\circ} 37^{\prime} 48.6^{\prime \prime} \mathrm{N}, 4^{\circ} 14^{\prime} 46.3^{\prime \prime} \mathrm{W}\right)$ is a $4 \mathrm{~km}$ long by $1 \mathrm{~km}$ broad spit dune system, about 600 to $800 \mathrm{yr}$ old, at the mouth of the Burry Inlet, south Wales. It comprises an area of blown sand overlying glacial till. The sands act as a small, ridge-shaped, rainfed, unconfined aquifer perched over the impermeable till. The groundwater system attains a dynamic equilibrium between recharge and groundwater discharge to the western foreshore and, to a lesser degree, the eastern saltmarsh (Stratford et al., 2012; Robins et al., 2013). Part of this latter area supports one of the largest populations of Bryum marratii in Britain, first found here in April 2012 (Bosanquet, 2012).

The location (x-, y- and z-coordinates) of each Bryum marratii colony $(n=44)$ was recorded with a high-accuracy Leica Viva GS14 GPS (Leica Geosystems, Heerbrugg, Switzerland) in May 2017, during the previous study (Callaghan \& Farr, op cit.). Prior to the present fieldwork, height contours corresponding with the highest (4.99 maOD) and lowest (4.42 maOD) colonies of $B$. marratii were generated from $2 \mathrm{~m}$ horizontal resolution LIDAR terrain model data and plotted over recent aerial imagery. In the field, four transects were established, each $90 \mathrm{~m}$ long, starting $\mathrm{ca} 30 \mathrm{~m}$ above the highest contour and ending $\mathrm{ca} 30 \mathrm{~m}$ below the lowest (Figure 1). Along each transect, ten sample points were positioned at $10 \mathrm{~m}$ intervals. The location (x-, y- and z-coordinates) of each sample point was recorded using the above GPS unit, providing a positional accuracy of $<10 \mathrm{~mm}$ horizontal and $<15 \mathrm{~mm}$ vertical. Electric Conductivity (EC) within the soil at the surface of each sample point was measured 
with a Decagon 5TE probe (Decagon Devices, Pullman, USA). An Edelman $70 \mathrm{~mm}$ Combination Auger (Eijkelkamp Soil \& Water, Giesbeek, The Netherlands) was then used to remove unconsolidated material to a depth of $1 \mathrm{~m}$. Top soil depth was measured from the extracted material and, at sample points along three of the transects, soil texture was assessed according to NE (2008). Once the water level had stabilised within the hole created by the soil extraction, i.e. Rest Water Level (RWL), its distance from the soil surface was measured, as was $\mathrm{EC}$ within the water column, using the above probe, and $\mathrm{pH}$, using a Mettler Toledo SevenGo Pro meter (Mettler Toledo, Columbus, USA). Fieldwork was undertaken during 1517 May 2018. There was no significant rainfall immediately prior to or during this period. High tides occurred during the early morning and early evening.

Statistical analyses and graphics were undertaken in R (R Core Team, 2017). Spatial analyses and mapping were undertaken in Quantum GIS (Quantum GIS Development Team, 2017). Data for each parameter measured was split into three groups, corresponding with sample points above ('Zone A'), within ('Zone B') and below ('Zone C') the elevation limits of Bryum marratii within the study area. The Kruskal-Wallis test (Kruskal \& Wallis, 1952) was used to test for significant difference in measured parameters between groups, with post hoc testing for difference in parameters between specific pairs of groups undertaken with the Conover-Iman test (Conover \& Iman, 1972).

A summary of the data obtained is provided in Table 1 and a plot of the data for an example transect is shown in Figure 2. All parameters measured were significantly different between zones, except top soil depth (Table 1). Soil surface elevation, RWL elevation and water $\mathrm{pH}$ declined from Zone A to Zone C (Figure 2). RWL distance from soil surface did not differ significantly between Zones B and C $(\alpha=-1.61 ; p=0.11)$, but that of Zone A was significantly deeper below ground than in Zone B $(\alpha=-6.69 ; p<0.01)$ and Zone $\mathrm{C}(\alpha=$ 8.08; $p<0.01$ ) (Figures $2 \mathrm{a}$ and 3 ). EC at the soil surface and within the water column increased from Zone A to Zone C, dramatically so between Zones B and C (Figures 2b, 4 and 5). Top soil texture also differed between zones, mainly comprising a sandy loam in Zone A, a sandy clay loam in Zone B and a silty clay in Zone C (Table 2). In almost all cases $(n=39)$, the top soil was underlain by sand throughout the remaining $1 \mathrm{~m}$ core. Only one core showed a difference from this trend, located at the end of a transect (T4) on the main saltmarsh plain, where a $20 \mathrm{~cm}$ silty clay tidal flat deposit lay above a $20 \mathrm{~cm}$ sand layer, which lay above further silty clay for the remainder of the core. 
The results of this study show the population of Bryum marratii at Whiteford Burrows grows upon a shallow sandy loam to sandy clay loam soil overlying deep sand. Whilst no visible signs of surface discharge were evident in the area during the study, except at one specific point (SS44637.94926) where very slow surface water movement was observed, the water table lies close to the ground surface throughout the elevation zone occupied by the moss, whereas upslope it is significantly below ground. The high permeability of the underlying sand, ca $10 \mathrm{~m} \mathrm{~d}^{-1}$ (Robins et al., 2013), coupled with a downslope hydraulic gradient and EC values indicating relatively low salinity, suggest a flow path from the unconfined dune aquifer that results in diffuse discharge across the habitat of $B$. marratii.

A relationship between Bryum marratii and the dune aquifer means the future of the moss is partly dictated by the condition of the latter, which increases risk. For example, there have been significant fluctuations in the water table elevation at Whiteford Burrows over the past 200 years, primarily due to change in dune spit morphology, and, notably, following a severe storm in March 1995 that caused significant foreshore erosion, resulting in a $6 \%$ decline in mean summer groundwater levels, a $1 \%$ decline in winter levels and a significant increase in drought magnitude, frequency and duration (Robins \& Jones 2012; Robins et al., 2013). Subsequent erosion of the foredunes by up to $2 \mathrm{~m} \mathrm{yr}^{-1}$ began to stabilise by 2005, when accretion started to replenish the foreshore. The water table has since slowly recovered to pre-1995 levels in large parts of the dune system (Robins et al., 2013). The effect on Bryum marratii from such changes are unknown, though potentially damaging, underlining the need to establish a population monitoring scheme for the species within this dynamic system, especially considering further risks associated with climate change, such as rising sea level and more frequent and severe storm events (Saye \& Pye, 2007), and possible changes in grazing management (Fowles \& Guest, 2006). This should be coupled with experimental research to investigate tolerance of the moss to varying levels of desiccation, $\mathrm{pH}$ and salinity, so that its habitat requirements may be better understood.

\section{Acknowledgements}

Funding for this work was provided by WREN. Many thanks to Colin Cheesman (Plantlife) for handling the research contract and to The National Trust for site access permission. Various information was kindly provided by Sam Bosanquet (Natural Resources Wales). Gareth Farr publishes with the permission of the executive director, British Geological Survey (Natural Environment Research Council). This study uses data from The Mumbles 
tidal gauge, provided by the British Oceanographic Data Centre. It also uses LIDAR data, licensed under the Open Government Licence v3.0.

\section{ORCID}

Des Callaghan https://orcid.org/0000-0002-0415-1493

Taxonomic Additions and Changes: Nil.

\section{References}

Bosanquet, S.D.S. 2012. Baltic Bryum Bryum marratii in south Wales. Unpublished report, Natural Resources Wales.

Callaghan, D.A. \& Farr, G. In press. The unusual inter-tidal niche of the rare moss Bryum marratii. Journal of Bryology.

Conover, W.J. \& Iman, R.L. 1979. On multiple-comparisons procedures. Technical Report LA-7677-MS. Los Alamos Scientific Laboratory.

Fowles, A. \& Guest, D. 2006. Narrow-mouthed Whorl Snail Vertigo angustior at Whiteford Burrows. In: Hurford, C. \& Schneider, M. (eds.). Monitoring nature conservation in cultural habitats: a practical guide and case studies. Dordrecht: Springer. pp. 259-70.

Kruskal, W.H. \& Wallis, W.A. 1952. Use of ranks in one-criterion variance analysis. Journal of the American statistical Association, 47: 583-621.

NE. 2008. Soil texture. Natural England Technical Information Note TIN037. Peterborough: Natural England.

Quantum GIS Development Team. 2017. Quantum GIS Geographic Information System. Open Source Geospatial Foundation Project. http://qgis.osgeo.org

R Core Team. 2017. R: a language and environment for statistical computing. Vienna: $\mathrm{R}$ Foundation for Statistical Computing.

Robins, N.S. \& Jones, M.L.M. 2013. Ecohydrological ‘indicators of alteration' - a robust measure of change in dune slacks. Ecohydrology, 6: 256-63. 
Robins, N.S., Pye, K. \& Wallace, H. 2013. Dynamic coastal dune spit: the impact of morphological change on dune slacks at Whiteford Burrows, South Wales, UK. Journal of Coastal Conservation, 17: 473-82.

Saye, S.E. \& Pye, K. 2007. Implications of sea level rise for coastal dune habitat conservation in Wales, UK. Journal of Coastal Conservation, 11: 31-52.

Stratford, C.J., Robins, N.S., Clarke, D., Jones, L. \& Weaver, G. 2013. An ecohydrological review of dune slacks on the west coast of England and Wales. Ecohydrology, 6: 162-71. 
Table 1. Summary data from sample points $(n=40)$ and test for difference between zones.

\begin{tabular}{|l|c|c|c|c|}
\hline \multirow{2}{*}{ Parameter } & \multicolumn{3}{|c|}{ Zone $^{\mathbf{a}}$} & Kruskal- \\
\cline { 2 - 5 } & $\begin{array}{c}\mathbf{A} \\
(\boldsymbol{n}=\mathbf{1 1})\end{array}$ & $\begin{array}{c}\mathbf{B} \\
(\boldsymbol{n}=\mathbf{1 5})\end{array}$ & $\begin{array}{c}\mathbf{C} \\
(\boldsymbol{n}=\mathbf{1 4})\end{array}$ & Wallis $\chi^{\mathbf{2} \mathbf{b}}$ \\
\hline $\begin{array}{l}\text { Soil surface elevation } \\
(\mathrm{maOD})\end{array}$ & $\begin{array}{c}5.55 \\
(5.17-5.90)\end{array}$ & $\begin{array}{c}4.55 \\
(4.25-5.0)\end{array}$ & $\begin{array}{c}4.02 \\
(3.73-4.19)\end{array}$ & $34.5^{*}$ \\
\hline RWL elevation (maOD) & 5.12 & 4.51 & 4.02 \\
& $(4.94-5.30)$ & $(4.25-4.86)$ & $(3.68-4.19)$ & $25.7^{*}$ \\
\hline $\begin{array}{l}\text { RWL distance from soil } \\
\text { surface }(\mathrm{m})\end{array}$ & -0.43 & -0.04 & -0.01 & $34.5^{*}$ \\
\hline Top soil depth $(\mathrm{m})$ & $(-0.68--0.20)$ & $(-0.23-0.02)$ & $(-0.09-0)$ & \\
\hline EC soil surface $(\mu \mathrm{S} / \mathrm{cm})$ & 0.17 & 0.22 & 0.32 & 5.4 \\
& $(0.04-0.42)$ & $(0.01-0.38)$ & $(0.19-0.80)$ & \\
\hline EC water column $(\mu \mathrm{S} / \mathrm{cm})$ & 210 & 1200 & 15,200 & $34.3^{*}$ \\
& $(100-440)$ & $(390-3300)$ & $(3900-23,100)$ & \\
\hline pH water column & 320 & 780 & 10,200 & $31.6^{*}$ \\
& $(170-550)$ & $(230-1200)$ & $(1500-23,100)$ & \\
\hline
\end{tabular}

${ }^{a}$ Measures summarised as mean and, in parenthesis, range. See main text for definition of zones.

${ }^{b}$ Kruskal-Wallis $\chi^{2}$ test for difference between zones, with significant $(p \leq 0.05)$ values highlighted by an asterisk.

Table 2. Count of top soil texture types at sample points $(n=30)$ within zones. See main text for definition of zones.

\begin{tabular}{|l|c|c|c|}
\hline \multirow{2}{*}{ Soil texture } & \multicolumn{3}{|c|}{ Zone } \\
\cline { 2 - 4 } & A & B & C \\
\hline Sandy Loam & 7 & 4 & 4 \\
\hline Silty Clay Loam & & 8 & 7 \\
\hline Silty Clay & & & \\
\hline
\end{tabular}


Figure captions

Figure 1. Location of Bryum marratii colonies, elevation limits and sample transects, labelled T1 to T4, at study site. Satellite image (C) 2017 Google, DigitalGlobe. LIDAR data (C) Natural Resources Wales.

Figure 2. Plot of data from example transect (T3). Vertical exaggeration of section (a) $x 8$. See text for definition of zones. Predicted Mean High Water Spring (MHWS) tide for 2008-2016 (4.54 maOD) is indicated, obtained from The National Tidal and Sea Level Facility, The National Oceanography Centre (NOC).

Figure 3. Boxplot of Rest Water Level distance from soil surface between zones.

Figure 4. Boxplot of soil Electric Conductivity at surface between zones. Note log scale of $y$ axis.

Figure 5. Boxplot of water Electric Conductivity at Rest Water Level between zones. Note $\log$ scale of $y$-axis. 


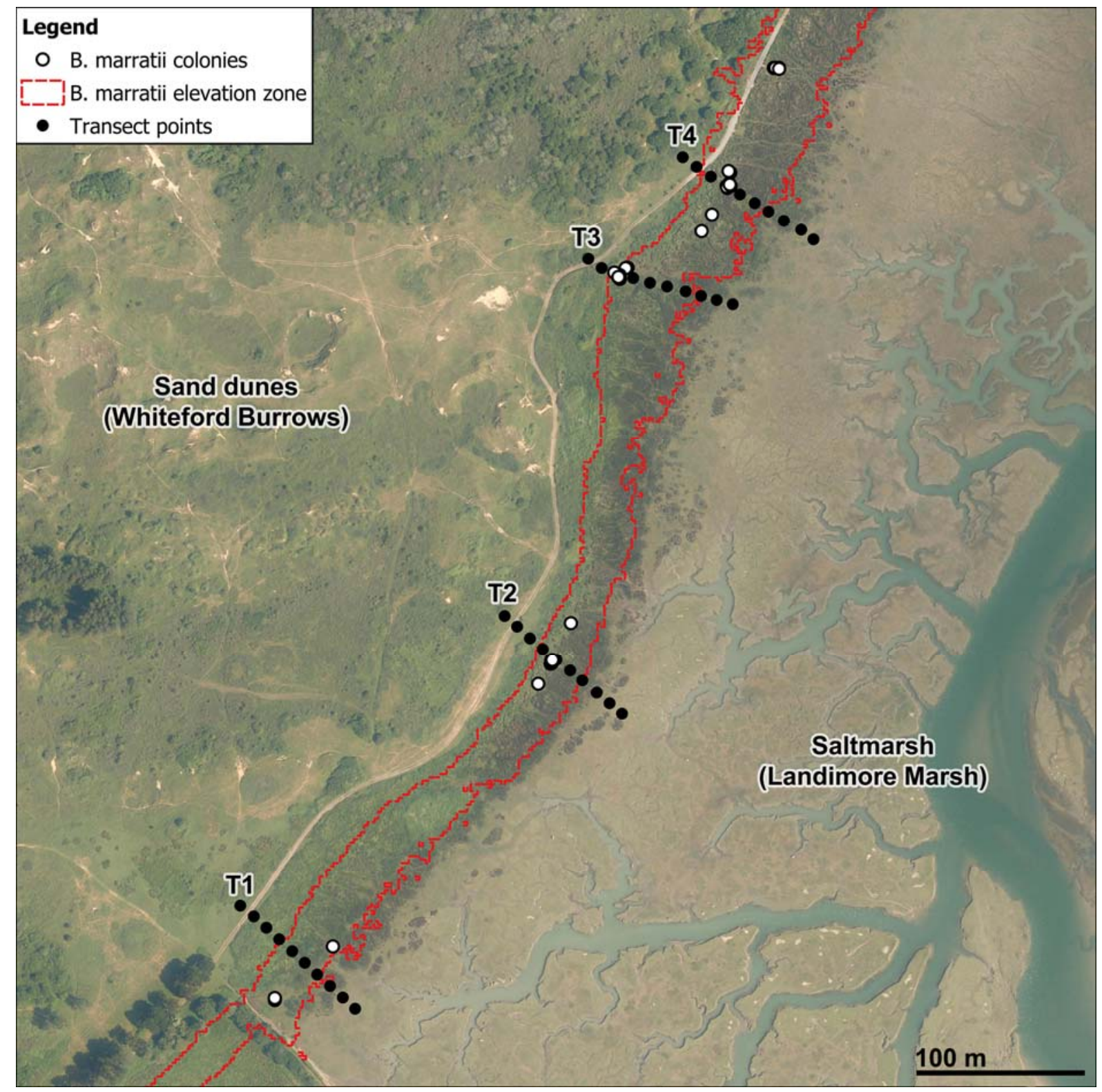

FIG 1 

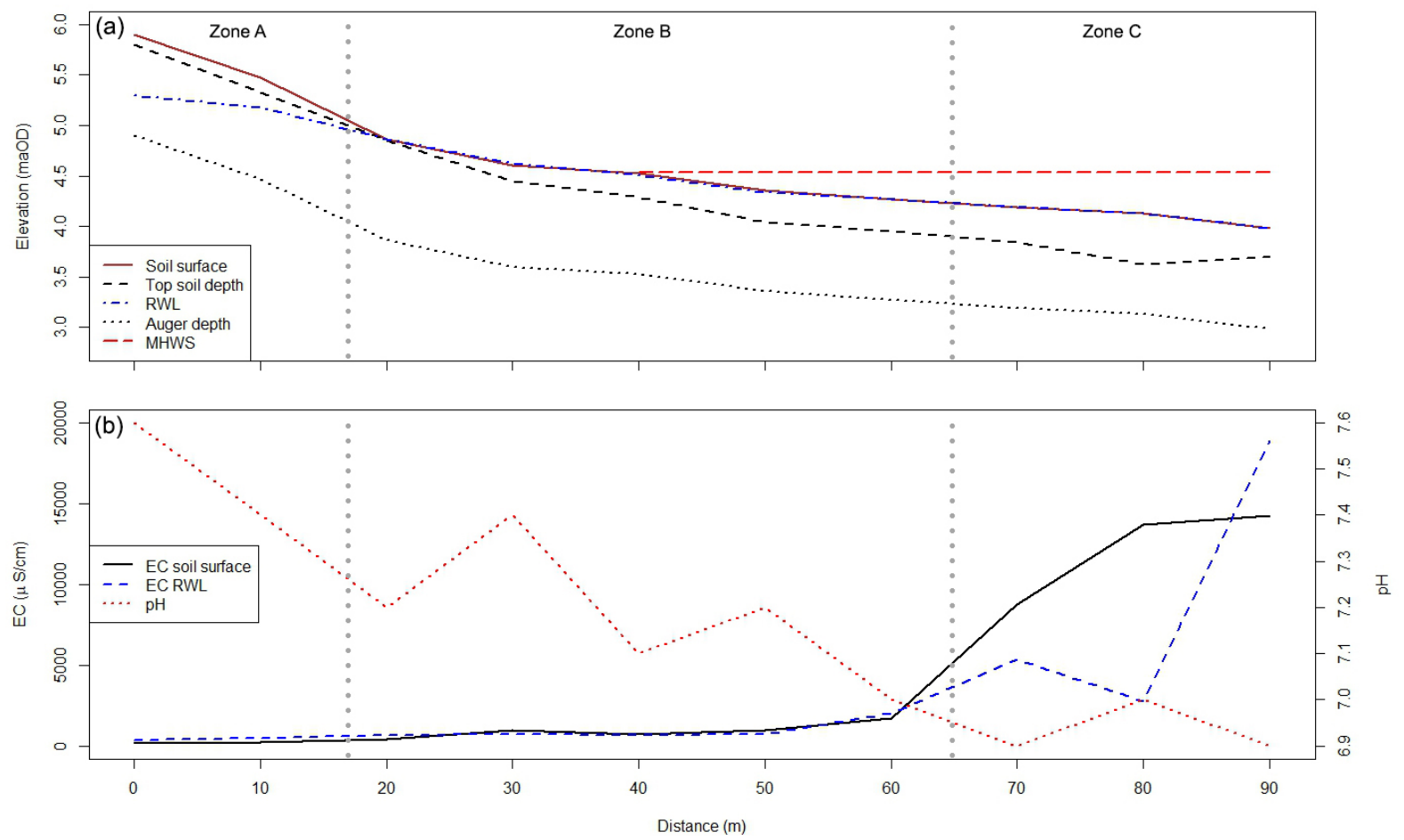

FIG 2 


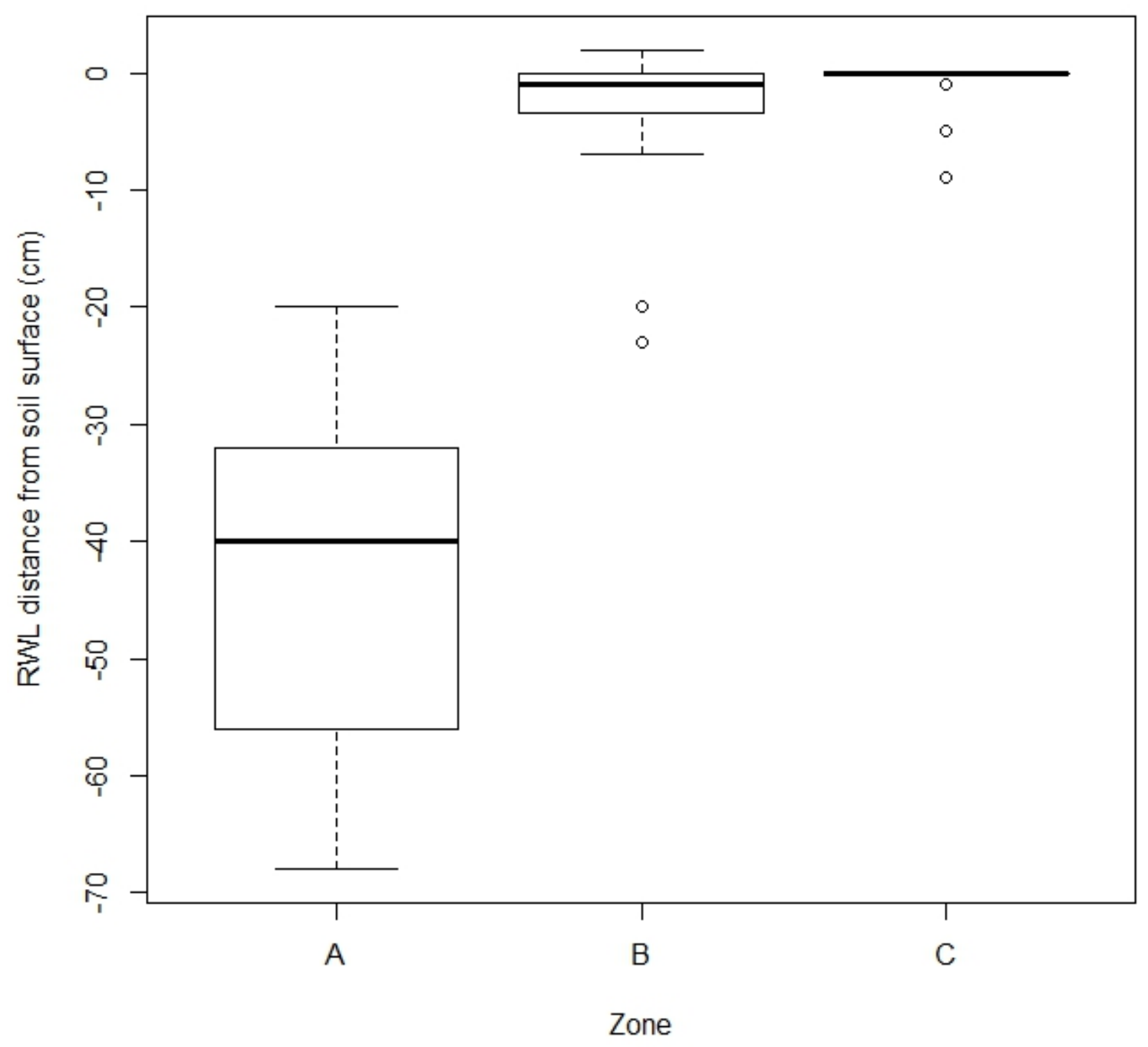

FIG 3 


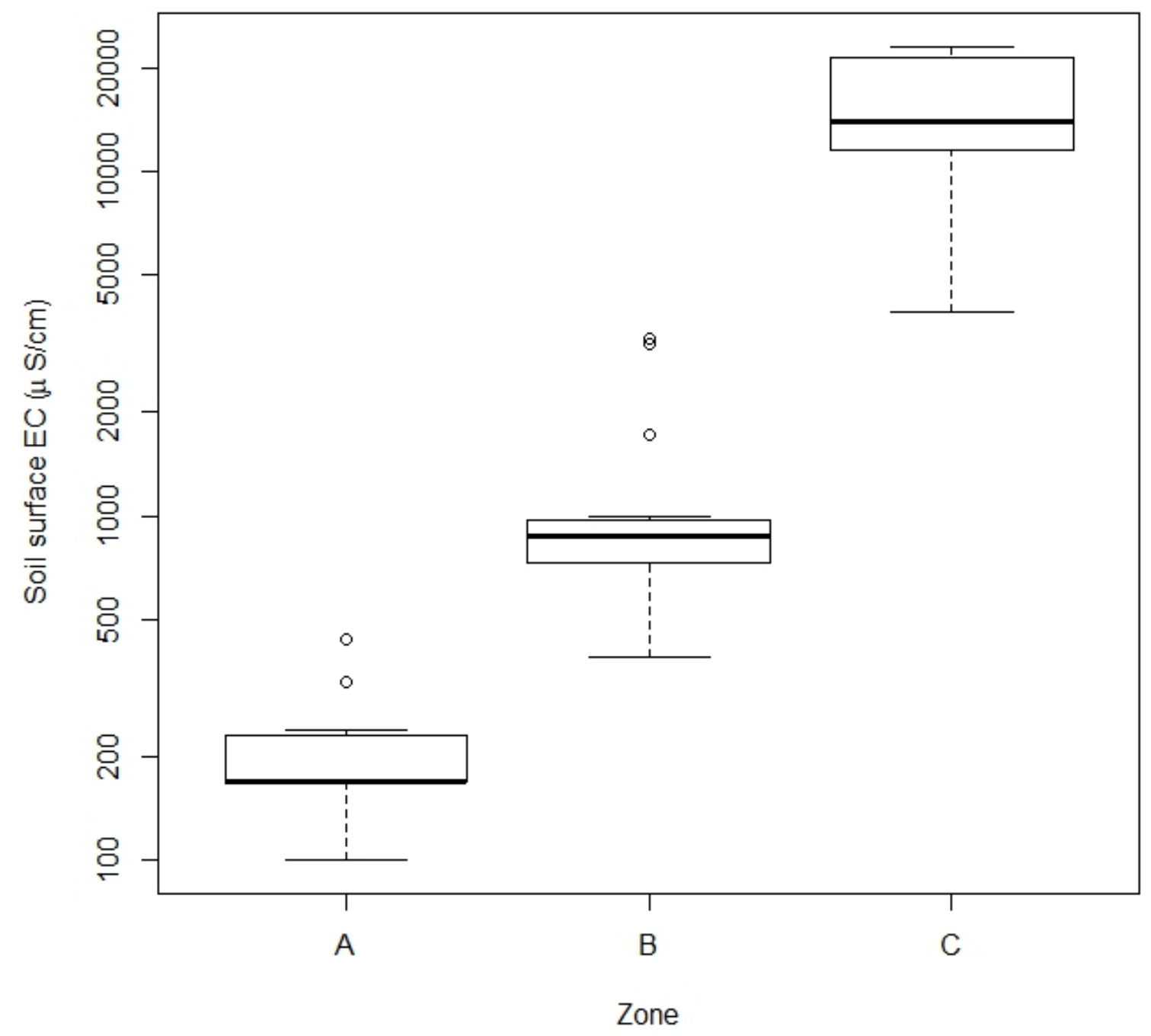

FIG 4 


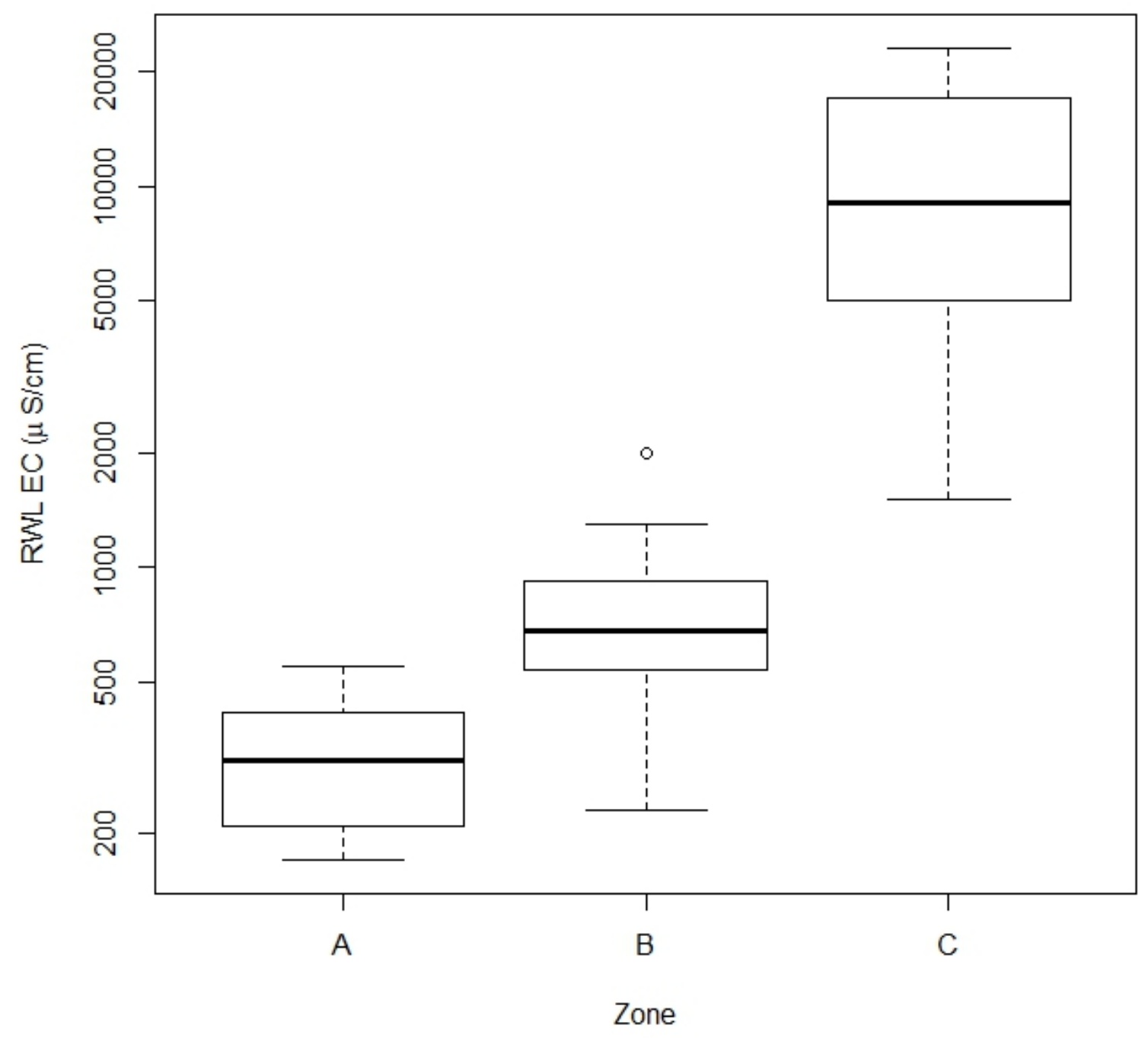

FIG 5 